\title{
¿Es sostenible el constructivismo radical?
}

\author{
IS RADICAL CONSTRUCTIVISM TENABLE?
}

Dr. Alfredo Gaete (agaetes@uc.cl) Campus Villarrica, Universidad Católica de Chile (Villarrica, Chile)

\begin{abstract}
In this work I try to show that radical, epistemological constructivism is an untenable thesis. Not so much because the arguments in favor of such a thesis are deficient, but because there are crucial problems that no constructivist seems to have solved and that must be solved in order for it to be possible to even formulate the thesis in question. I also mention a consequence that these considerations have in education.
\end{abstract}

Key words: constructivism, radical constructivism, metaphysical realism, epistemology, educational theory.

\section{Resumen}

En este trabajo intento mostrar que el constructivismo epistemológico radical es un tesis insostenible, no tanto porque los argumentos a favor de dicha tesis sean deficientes sino porque hasta ahora existen problemas cruciales que ningún constructivista parece haber resuelto y que, sin embargo, deben ser resueltos para poder siquiera formular la tesis en cuestión. También me refiero a una consecuencia que estas consideraciones tienen en educación.

Palabras clave: constructivismo, constructivismo radical, realismo metafísico, epistemología, teoría educativa

1

Hay una manera de concebir el conocimiento humano que ha ganado mucho prestigio en buena parte de las ciencias sociales y también, creo, aunque quizá en menor grado, en la filosofía latinoamericana y europea. Me refiero a la idea de que nuestro conocimiento del mundo es resultado de nuestras propias operaciones cognitivas $y$ no del influjo de una realidad que existe con independencia de que la conozcamos - una realidad "externa" u "objetiva". Conocer, según esta visión, es una actividad constructiva más que receptiva: no consiste en representarse un mundo que está dado "ahí afuera", sino en crear o construir realidades. De ahí que a los partidarios de esta concepción se les diga "constructivistas".

Se trata, por cierto, de una concepción bien controvertida -una que, como apuntara von Glasersfeld (1984) en su An Introduction to Radical Constructivism, parece chocar no sólo con la visión tradicional del mundo sino incluso con el sentido común. Por lo mismo, el constructivismo tiene el mérito de hacernos reflexionar sobre cosas que tendemos a dar por sentado sin mayor crítica. Pero es precisamente debido a su naturaleza altamente contraintuitiva que uno esperaría que sus defensores presentaran argumentos bien sólidos a favor suyo; cosa que, hasta ahora, no parece haber sido el caso (1). Y creo que nunca lo será, por la sencilla razón de que, si estoy en lo cierto, la concepción constructivista del conocimiento es simplemente insostenible. Es esto lo que intento mostrar en las líneas que siguen.

Primero (en la sección 2) voy a detallar lo mejor que pueda la visión de la que estoy hablando, porque lo cierto es que el término "constructivismo" tiene distintas acepciones y, además, se puede ser constructivista no sólo sobre el 
conocimiento sino sobre una gran variedad de cosas (2). Después (en la sección 3) introduciré una idea que la epistemología constructivista necesita para ser sostenible y puntualizaré un problema bien serio que dicha idea engendra y que, hasta donde yo sé, nadie ha resuelto. Finalmente, (en la sección 4) me referiré a una consecuencia que estas reflexiones debieran tener específicamente en el terreno educativo -que es, creo, uno de los sectores que más ha recibido el influjo del constructivismo, al menos a nivel del discurso.

2

Partamos consignando que el término "constructivismo" no se usa sólo para referir la posición epistemológica que acabo de delinear. Por un lado, aparte del conocimiento hay muchas otras cosas sobre las cuales uno puede ser constructivista: la belleza, la etnia, los trastornos mentales, la identidad, los números, el género sexual, las partículas elementales, el tiempo, las emociones, etc. Estas y muchas cosas más han sido postuladas como construidas antes que "dadas" (3). En consecuencia, hay varios constructivismos que pueden no tener ninguna implicancia a nivel epistemológico (4). Algunos de estos constructivismos son bastante plausibles, pero aquí voy a discutir sólo el constructivismo epistemológico: la tesis de que el sujeto cognitivo construye el mundo (o los mundos) que conoce. Cuando hable de "constructivismo", entonces, me estaré refiriendo exclusivamente a este constructivismo acerca del conocimiento.

Además, es posible distinguir una versión suave del constructivismo y una versión fuerte o, como se dice a veces, radical. La versión suave acepta que el conocimiento está determinado no solamente por las operaciones que realiza el sujeto cognitivo al conocer, sino también por una realidad objetiva o externa. La idea kantiana de que el sujeto le impone sus categorías al mundo sintetiza bastante bien esta línea de pensamiento. Aquí se deja espacio a la participación de lo objetivo en la actividad cognitiva humana: se acepta que, además de las construcciones efectuadas por nuestra subjetividad, existe una realidad "en sí", un mundo que no depende en ningún grado de ningún sujeto cognitivo.

En cambio, el constructivismo radical pone toda la responsabilidad constructiva en el sujeto. Tal como señala von Glasersfeld: "el constructivista radical ha renunciado de una vez y para siempre al realismo metafísico" (1984:24). El realismo metafísico es la tesis de que existe una realidad objetiva, independiente del sujeto que la conoce. No es que el constructivista radical niegue forzosamente el realismo metafísico (se puede ser constructivista epistemológico sin ser constructivista metafísico). Lo que niega es la necesidad de adherir al realismo metafísico. A veces se habla de "poner la objetividad entre paréntesis". La idea es que nuestro conocimiento no requiere la participación de ninguna realidad que esté más allá de nuestra subjetividad o intersubjetividad. Incluso si una realidad como ésa existiera, aun así no jugaría ningún papel en nuestro saber. En palabras de Shapin y Schaffer: "Tan pronto como reconocemos el status convencional y de artefacto de nuestras formas de conocimiento, estamos en condiciones de advertir que somos nosotros y no la realidad los responsables de lo que sabemos" (1985:344, las itálicas son mías).

En lo que a mí respecta, la versión suave del constructivismo no es mayormente problemática. De hecho, me parece trivialmente cierta y no creo que en la actualidad tenga muchos detractores. Yo ni siquiera me referiría a ella como "constructivismo". Como sea, lo que me interesa discutir en este ensayo es el constructivismo radical. Porque es ésta la visión altamente contra-intuitiva que, gracias al influjo de pensadores como Richard Rorty, Heinz von Foerster, Ernst von Glasersfeld y Humberto Maturana, entre muchos otros, ha ganado especio en las últimas décadas, sobre todo en Latinoamérica y Europa (5). Otras figuras usualmente asociadas al constructivismo epistemológico no adhieren, a mi juicio, a la versión radical del mismo. Me refiero a pensadores como Kant y Piaget, por ejemplo, ninguno de los cuales, a mi entender, rechaza la necesidad del realismo metafísico. 
Así entendido, el constructivismo es una tesis revisionista más que descriptiva. No intenta describir la manera en que de hecho concebimos el conocimiento, sino prescribir otra manera de hacerlo. Dicho de otro modo, lo que propone el constructivista radical es una reconceptualización del conocimiento: una revisión del concepto tradicional de conocimiento, según el cual conocer implica entrar en contacto con una realidad que, al menos en parte, no depende del sujeto cognitivo. Ésta es la manera en que, desde la antigua Grecia y hasta bien entrado el siglo XX, la mayoría de los epistemólogos "occidentales" había pensado las cosas. "Conocer" algo significaba representarse una realidad que estaba "ahí afuera" para ser conocida y que, de hecho, en último término causaba los procesos y estados por los cuales se llevaba a cabo esa representación. El constructivismo radical invierte esta relación causal: quiere que dejemos de pensar en la realidad como algo que causa ciertos estados o procesos cognitivos en nosotros y la empecemos a ver más bien como un efecto de esos estados y procesos cognitivos -en otras palabras, que dejemos de concebir el conocimiento como una recepción o captación de información sobre el mundo y que empecemos a verlo como una actividad constructiva que se efectúa sin miramientos respecto de lo que haya más allá de nuestra cultura y nuestra mente, si es que de hecho hay algo más que eso.

Debe notarse también que no todos los constructivistas radicales coinciden respecto de quién es en última instancia el sujeto cognitivo, esto es, de qué sujeto hemos de predicar correctamente expresiones tales como "conoce" o "sabe que ...". Algunos lo identifican con el sistema nervioso, otros con la persona, otros con el sistema social, etc. (6). Cada una de estas variantes arroja resultados bien diferentes, pero todas ellas niegan la necesidad de adherir al realismo metafísico. O sea, más allá de si el que conoce se ubica, en último término, a nivel personal, sub-personal o supra-personal, lo que distingue al constructivista radical es su desdén por el realismo. Pero es justamente este desdén lo que, a mi juicio, hace que su postura sea insostenible, tal como intentaré mostrar a continuación.

3

El constructivismo radical descansa necesariamente sobre la idea de que el mundo fenoménico -esto es, el mundo que se nos presenta o aparece en la experiencia consciente- no es ni se debe a una realidad externa sino a nuestros propios procesos perceptivos. Se supone, por ejemplo, que la experiencia visual que tiene una persona al ver un volcán en frente suyo no se debe a que haya realmente algo en frente suyo, en el sentido de un objeto que existe con independencia de que ella o alguien más lo vea. El volcán percibido es enteramente un resultado del proceso perceptivo; y si hay o no algo así como una realidad "en sí", una realidad que no presupone la existencia de un sujeto percipiente, es simplemente irrelevante para la existencia del volcán. Llamémosle a esta idea "constructivismo fenoménico" (7).

Que el constructivismo epistemológico radical presupone necesariamente el constructivismo fenoménico queda claro si se considera lo siguiente. Buena parte de nuestro conocimiento, específicamente el así llamado "conocimiento empírico", es acerca de -y se basa en- los objetos que se nos presentan en la experiencia (8). Así, por ejemplo, si sabemos que el pasto es verde y la nieve es blanca, o que el sistema nervioso se compone de neuronas, o que China es actualmente el país más populoso del planeta, es porque alguien (nosotros mismos u otras personas) ha realizado ciertas "observaciones" o "mediciones". Es en virtud de las experiencias provenientes de esas observaciones o mediciones que hemos podido llegar a saber cosas de este tipo. Pero si el constructivismo fenoménico resultara ser falso, esto es, si nuestra experiencia dependiera en algún grado de una realidad objetiva, entonces nuestro conocimiento empírico, que depende (parcialmente) de la experiencia, dependería a su vez de esa realidad objetiva (en algún grado). En otras palabras, habría que aceptar el realismo metafísico y, en consecuencia, rechazar el constructivismo radical. 
Y eso es, creo, justamente lo que hay que hacer. Porque el constructivismo fenoménico tiene al menos un serio problema -uno lo suficientemente serio como para echar por la borda todo el proyecto constructivista. Este problema se produce debido a cierta característica de varias de nuestras experiencias perceptuales: a saber, su intersubjetividad. A menudo dos o más personas perciben la misma cosa; por ejemplo, ven el mismo volcán, o escuchan la misma explosión, o gustan el mismo helado, etc. Para decirlo en jerga filosófica, sus percepciones tienen el mismo "objeto intencional": son percepciones de lo mismo, o sobre lo mismo, o dirigidas a lo mismo (el mismo volcán, la misma explosión, etc.). Esto no quiere decir que las experiencias sean idénticas. De hecho, es poco plausible que lo sean, al menos porque toda experiencia perceptual se tiene desde la perspectiva particular del sujeto que la tiene. Pero más allá del hecho innegable de que, por ejemplo, al contemplar el volcán Villarrica dos observadores pueden tener experiencias visuales radicalmente distintas, ambas son sobre el mismo volcán. Su experiencia es intersubjetiva porque ambos ven el mismo objeto, aun cuando lo vean desde distintos puntos de vista y, por tanto, se trate de experiencias cualitativamente distintas.

El problema que debe afrontar el constructivista fenoménico es el de explicar qué significa que dos (o más) experiencias perceptuales tengan el mismo objeto. Por ejemplo, cuando en su cotidianeidad acepta sin mayores reparos que el volcán que ha visto y fotografiado es el mismo que han visto y fotografiado sus amigos, ¿a qué se refiere con "el mismo"? No puede querer decir que su percepción visual y la de sus amigos (o las fotografías tomadas) son parcialmente causadas por el mismo objeto externo, porque la necesidad de postular objetos de ese tipo es precisamente lo que quiere negar. Esto es, no puede entender la expresión "percepción de lo mismo" (o "experiencia perceptual intersubjetiva") como significando percepción causada por un mismo objeto externo, porque cualquier interpretación pertinente de una expresión como esa lo comprometería con el realismo metafísico. Tampoco puede decir que significa algo así como experiencia visual idéntica, ya que, tal como hemos puntualizado en el párrafo anterior, que dos personas vean lo mismo no implica que tengan la misma experiencia. Si yo contemplo el volcán Villarrica desde el oeste usando gafas de sol tendré una experiencia bien diferente a la que tendrá alguien que lo contempla desde el este usando binoculares, pero eso no quiere decir que no estemos viendo el mismo volcán (el volcán Villarrica).

Aquí el constructivista radical parece estar forzado a tomar una de las siguientes dos rutas. Por una parte, podría lisa y llanamente negar que tengamos derecho a hablar de experiencias perceptuales intersubjetivas -que cuando describimos a la gente como viendo el mismo volcán, o escuchando la misma explosión, estamos hablando de manera figurativa 0 , sencillamente, cometemos un error. Desde esta perspectiva, la intersubjetividad es un mito. Por otra parte, el constructivista puede aceptar la intersubjetividad y apelar a que "percepción de lo mismo" significa percepción causada por un mismo objeto, pero negar que se trate de un objeto externo.

Cualquiera de estas dos rutas, sin embargo, es altamente problemática también. El problema de la primera es que, además de ser implausible, pone al constructivista en contra de uno de sus más queridos fetiches: la ciencia. En efecto, no sólo la gran mayoría de los constructivistas radicales son hombres y mujeres de ciencia, sino que algunos de ellos apelan a la investigación científica (por ejemplo en biología o en psicología o en antropología) como un modo de dar sustento a su epistemología constructivista. Pero sin intersubjetividad la actividad científica es sencillamente imposible. Porque dicha actividad requiere (y espero que esto sea lo suficientemente obvio como para no tener que ahondar en ello) que la comunidad científica pueda, si no en efecto al menos en principio, hacer observaciones sobre lo mismo. De manera que si no estamos justificados en creer que observaciones como éstas son factibles, tampoco lo estamos para pensar que la actividad científica lo es. Lo cual explica, supongo, que no sea fácil encontrar muchos constructivistas que sigan de buena gana esta ruta argumentativa (9). 
El problema de la segunda ruta, por otra parte, es que conduce a otra encrucijada. Supongamos que "percepción de lo mismo" refiere a la percepción causada por un objeto no-externo, uno cuya existencia no depende de una realidad objetiva. Este objeto es o bien perceptible o bien no perceptible. En el primer caso, dos o más observadores podrían percibirlo, de modo que volvemos al mismo problema del que queríamos escapar (porque tenemos que explicar, de nuevo, qué quiere decir que dos o más observadores perciben lo mismo). En el segundo caso, nos enfrentamos con la dificultad de explicar qué clase de objeto es este objeto imperceptible que, sin embargo, tiene propiedades causales -una dificultad que nos puede llevar muy pronto al dualismo de substancia y a todos los bien conocidos (y aún no resueltos) problemas asociados a esa posición metafísica.

Hasta que alguien ofrezca una salida clara y satisfactoria a las dificultades de cualquiera de estas dos rutas, el constructivismo fenoménico y, por extensión, el constructivismo radical, carecerán de justificación. Porque el peso de la prueba recae sobre los revisionistas, no sobre los que tienen concepciones más tradicionales. A falta de argumentos, la posición que se impone es la de sentido común, no la que parece descabellada. En otras palabras, el realismo metafísico no precisa de defensa alguna a menos que alguien logre hacer una defensa mínimamente razonable del constructivismo radical. Pero esta defensa parece estar a años luz de distancia cuando se consideran las dificultades asociadas al constructivismo fenoménico.

En suma, la concepción constructivista del conocimiento es o bien falsa o, en el mejor de los casos, insostenible por el momento. Sería, pues, procedente que el espacio que dicha concepción ha ganado en nuestras escuelas de psicología, antropología, sociología, educación y filosofía fuese seriamente revisado.

\section{4}

El problema de la intersubjetividad es apenas uno de los problemas no resueltos por el movimiento constructivista. Otras críticas serias a esta posición epistémica tampoco parecen haberse contestado exitosamente. Este estado tan precario de la justificación del constructivismo contrasta bastante con el grado de aceptación que, sin embargo, se le ha dado en las disciplinas mencionadas. No deja de sorprender, en efecto, que investigadores y profesionales dotados de un pensamiento tan crítico como el que se requiere para hacer filosofía y ciencias sociales se rindan tan fácilmente -tan acríticamente- ante una tesis defendida de manera tan deficiente.

El caso de la educación es especialmente llamativo. Aquí el constructivismo se ha convertido en una especie de ideología totalizadora, algo así como la única posición razonable. En esta línea, Anguita reportaba haber "oído decir a profesores de Enseñanza Secundaria, biólogos y geólogos, que tienen la sensación de estar obligados a adoptar no sólo el enfoque, sino también la jerga del constructivismo cuando redactan cualquier documento de índole pedagógica, como son las programaciones del Departamento o el Centro" (2001:238).

¿Qué es lo que ha hecho tan penetrante al discurso constructivista en esta disciplina? Al menos parte de la respuesta ha sido sugerida por McCarty y Schwandt: "A pesar de serios problemas ... en aspectos epistemológicos y educacionales del constructivismo radical ... esta filosofía continúa siendo seductora para los educadores ... (porque) encaja con el lenguaje contemporáneo políticamente correcto sobre la construcción del género, el ser y la identidad ... resonando con una actitud popular anti-clase dirigente, ideología anti-autoritaria e irónica ... Le presta apoyo a ataques en gran escala a la psicología conductista ... sugiere que las maestras deben ser libres de ... estructuras basadas en la disciplina para poder determinar actividades curriculares por sí mismas ... y que todos los participantes son más o menos iguales" (citados en Chadwick 2005:5). 
Está claro que el constructivismo fue útil para poner de relieve los defectos de la psicología conductista y de sus implicaciones educacionales (las supuestas y las reales). Pero ello se debió mucho más a la valoración del mundo del significado y otras consideraciones "mentalistas" que al desprecio por la objetividad de la realidad o del conocimiento. En cualquier caso, desligarse del constructivismo radical de ningún modo implica volverse conductista. Por otra parte, en mi opinión actitudes contra el sexismo, el clasismo y el autoritarismo son todas importantes, pero ninguna de ellas se sigue lógicamente ni del constructivismo ni del realismo metafísico ni, en general, de ninguna posición filosófica respecto de la naturaleza de la realidad o del conocimiento. Un constructivista puede llegar a ser tan sexista o tan pro-autoritarismo como un realista metafísico (y como un conductista); $y$, a la inversa, el mero hecho de creer en la realidad externa no lo compromete a uno con ninguna actitud específica hacia el género o la democracia (10). Asimismo, el grado de libertad que las maestras debiesen tener para determinar actividades curriculares depende mucho más de la investigación empírica sobre el asunto que de este o aquel marco filosófico; y la igualdad de los participantes del proceso educativo, sea o no beneficiosa, tampoco es marca registrada del constructivismo radical.

No me extrañaría que también en otras disciplinas la asociación fortuita entre constructivismo y ciertos valores u otros aspectos deseables estuviese a la base de la aceptación relativamente acrítica de dicha visión. También puede ser que el uso laxo del término haya generado suficiente confusión como para inducir a pensar, por ejemplo, que uno tiene que ser constructivista epistemológico si quiere ser constructivista respecto de los trastornos mentales, o la identidad, o la etnia, etc. Espero que las consideraciones hechas en este trabajo hayan dejado en claro que ninguna de estas razones es una buena razón para ser constructivista; y que, como sea, más allá de estas razones, ninguna teoría educativa podrá hallar sustento en el constructivismo radical si no se resuelven los problemas teóricos que hacen de éste una postura insostenible. De modo que antes de presentarse como constructivistas, los teóricos de la educación harían bien en explicar con mayor detalle a qué se refieren con ello y cómo sostienen su opción. Para lo cual tienen que haber pensado -y bastante- sobre el asunto.

Antes de terminar, debo aclarar que no he mostrado aquí ningún problema o deficiencia en los argumentos a favor del constructivismo sino en la formulación de la tesis constructivista radical. Mi punto es que dicha tesis no puede ser siquiera formulada si el problema de la intersubjetividad no se resuelve explícitamente. Antes de considerar los argumentos a favor o en contra de cualquier tesis filosófica, la tesis debe ser presentada de manera inteligible. Pero este requerimiento básico no puede ser satisfecho ni por la tesis constructivista radical ni por ninguna otra tesis que amenace con privar de significado nuestro difundido (e inevitable) discurso respecto de la experiencia de lo mismo.

\section{Notas}

(1) Para el análisis crítico de los argumentos pro-constructivismo véase Searle (The Construction of Social Reality), Blackburn (Truth) y Boghosian (Fear of Knowledge. Against Relativism and Constructivism).

(2) Esto puede llevar a confusiones importantes. En psicología, por ejemplo, y tal como señala Raskin: "uno se topa con tantas variedades de psicología constructivista que incluso los expertos parecen desconcertados. Términos como 'constructivismo', 'construccionismo' y 'constructivo' se emplean de manera tan idiosincrática que por momentos parecen resistirse a toda definición" (2002:2). En educación, por su parte, uno puede encontrarse, según Chadwick (2005), hasta 25 variedades diversas de constructivismo.

(3) En su libro The Social Construction of What?, Hacking menciona más de 20 cosas que se han postulado como socialmente construidas. A éstas deben sumarse unas cuantas, además de las cosas que se supone que construyen 
no las sociedades o las culturas sino las personas -o sus sistemas nerviosos- de manera individual, si es que ello se admite.

(4) Yo mismo he defendido, por ejemplo, una forma de entender el concepto de trastorno mental según el cual los trastornos mentales serían algo así como construcciones culturales (Gaete 2008). Está claro que esta visión puede sostenerse independientemente de cuál sea la posición que uno tenga respecto de la naturaleza del conocimiento.

(5) En el mundo anglosajón, en cambio, pocos se han sentido atraídos por ella; al respecto véase Boghosian (Fear of Knowledge. Against Relativism and Constructivism).

(6) En algunos ámbitos se ha vuelto costumbre ya referir a los constructivismos más sociales como "construccionismo". Véase por ejemplo Burr (An Introduction to Social Constructionism) y Young y Collin (Constructivism and Social Constructionism in the Career Field. Journal of Vocational Behavior).

(7) Para una defensa de este tipo de constructivismo, véase por ejemplo Maurana y Varela (El Árbol del Conocimiento) y von Glasersfeld (1984).

(8) Esto es admitido incluso por los constructivistas. Así, por ejemplo, von Glasersfeld señala: “El mundo experiencial, sea el de la vida cotidiana o el del laboratorio, constituye el fundamento sobre el cual se testean nuestras ideas" (1984:24).

(9) A veces la objetividad se concibe o se reinterpreta como intersubjetividad; véase, por ejemplo, Nietzsche (The Genealogy of Morals) y Quine (The pursuit of truth). Desde mi punto de vista, propuestas en esta línea pasan por alto que no puede haber intersubjetividad sin una realidad objetiva.

(10) En este sentido (pero quizá no en otros), concuerdo con Quinton en que "no hay conexión lógica entre doctrinas filosóficas y actitudes morales o políticas" (citado en Watkins 1957:79).

\section{Bibliografía}

Anguita, F. 2001. Contra el constructivismo. Enseñanza de las Ciencias de la Tierra 9(3): 235-238.

Chadwick, C. 2005. Por qué no soy constructivista. Revista Brasileira de Aprendizagem Aberta e a Distância 4: 1-6.

Gaete, A. 2008. The concept of mental disorder. A proposal. Philosophy, Psychiatry, and Psychology 15(4): $327-339$.

Raskin, J. D. 2002. Constructivism in psychology: Personal construct psychology, radical constructivism, and social constructionism. En: J. D. Raskin \& S. K. Bridges. Studies in meaning: exploring constructivist psychology. New York: Pace University Press, pp. 1-25.

Shapin, S. y Schaffer, S. 1985. Leviathan and the air pump: Hobbes, Boyle, and the experimental life. Princeton: Princeton University Press.

Von Glasersfeld, E. 1984. An introduction to radical constructivism. En: P. Watzlawick. The invented reality. New York: Norton, pp. 17-40.

Watkins, J. W. N. 1957. Epistemology and politics. Proceedings of the Aristotelian society, New Series 58: 79-102. 
Recibido el 14 Oct 2012

Aceptado el 4 Ene 2013 